\title{
La imagen del día. Una revelación del fin(al)
}

The Image of the Day. A Revelation of the End

PatXi Lanceros

Universidad de Deusto

DOI: http://dx.doi.org/10.15366/bp2018.19.002 Bajo Palabra. II Época. No19. Pgs: 49-66 
Resumen

El Apocalipsis es uno de los textos más extraños y más influyentes de la historia occidental. El artículo repasa la vigencia cultural y social de ese curioso libro, y seńala algunos aspectos de la tradición que ha propiciado. A partir de esas claves, se interroga por la importancia del control del tiempo a través de la gestión del relato.

Palabras clave: fin, apocalipsis, historia, tiempo

\section{Abstract}

The Book of Revelation is one of the most influential texts in the Western history. This paper reviews its social and cultural validity and points out some strands of the tradition that it boosted. From this point of view, the importance of time control through storytelling will be studied.

Keywords: end, revelation, history, time. 


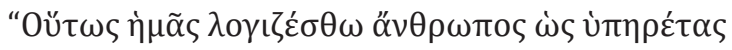

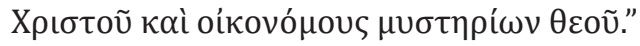

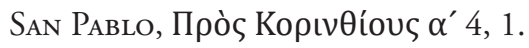

$\mathrm{L}$ a inminencia del fin, segura o supuesta, modifica la experiencia del tiempo. La proposición antecedente, que podría reclamar carácter de evidencia, es, cuando se trata de un fin y de un tiempo de incumbencia privada como cuando se piensa en un fin y en un tiempo de índole pública y/o de interés general. En ausencia de fin, el tiempo se dilata, se expande, hasta resultar imperceptible o in-diferente, hasta convertirse en espacio: y un espacio espectral o desértico, un espacio no marcado, no de-limitado, de-marcado o de-finido. Un espacio en el que es posible, y casi necesaria, cualquier suerte de dispersión, o de dis-tracción.

El fin inminente -sea el que atañe a una tarea o un trabajo, a una vida, a un proceso político-convierte el tiempo en plazo: no línea (si es que esa figura geométrica resultara adecuada para "dibujar" el tiempo), indefinida o infinita, sino ya segmento, clausurado por el día del juicio, que es el instante del vencimiento, el momento de la verdad, el momento en el que se piden, y se han de dar, cuentas. Con la vista puesta en el día decisivo, o ante el momento de la verdad, del cómputo o de la recapitulación, no valen distracciones o dispersiones. Por el contrario, la expectativa cualifica cada instante, que no puede ser ignorado, dilapidado o perdido; también lleva la experiencia a un grado máximo de tensión.

Podría decirse, y se dice en algunos foros, que el síndrome escatológico no afecta exclusivamente al humano, sino que forma parte de las estrategias defensivas de la vida en todos sus modos de proceder. $\mathrm{Y}$ es cierto que, a falta de poder determinar con exactitud el grado de con(s)ciencia y su distribución, creciente o no, en la cadena de la vida animal (dejemos al margen, por motivos casi obvios, la vegetal), o el funcionamiento de las pautas instintivas, parece que también los animales experimentan la (im)presión del fin(al), y que aceleran los ritmos y los movimientos cuando presienten términos y desenlaces. Lo que implica(ría) que tanto la premonición del fin(al) como la reacción en términos de estrés arraigan en la mera naturaleza. 
Pero no es la presunta pauta natural (una especie de extensión del instinto de supervivencia) sino la pauta cultural la que ahora nos interesa. $Y$ es que, efectivamente, la leyenda humana acumula una herencia de finales previstos, presentidos o anunciados que se insinúan ya desde los mismos comienzos del texto escrito y que se remontan a la pluralidad de tradiciones orales constituyéndose en la base (o en una de ellas) de la estructura narrativa. $\mathrm{O}$ en el horizonte de esa misma leyenda.

Pues, de hecho, las estructuras narrativas -ya las de los viejos mitos o las del cuento folklórico, pero también las de la novela, al menos hasta comienzos del siglo XXconjugan alternancia de tiempos y variación de ritmos: tramos en los que el tiempo de distiende y el fin se ignora o se oculta, largos o cortos periodos de oscilación, propicios para divagaciones, interpolaciones o excursos. Cierto es que en esos intervalos se van disponiendo signos, datos y pistas de orientación. Que, sin embargo, cobran sentido a la vista del fin: cuando el ritmo se acelera, cuando el tiempo se acorta, cuando cada decisión es ineludible e irreversible. En ese punto (en ese momento o en ese proceso) el personaje, individual o colectivo, alcanza (o es alcanzado por) la ocasión de la prueba; allí cobra y muestra su verdadera estatura, su genuina naturaleza: que suele ser resultado de la historia, aunque convoque, y porque lo hace, algún designio o destino, anterior o exterior.

La repetición del relato, la reiteración de narraciones orientadas al fin u orientadas desde el fin, es una constante; y es el cauce y el inmenso caudal del relato el que da formas (culturales) a la pauta, posiblemente natural, que enlaza fin, tiempo, movimiento, ritmo..., y que convierte al síndrome escatológico en uno de los momentos estructuralmente más importantes de la historia: si es que la historia misma no es sino una (u otra) composición que tiene, precisamente, en el síndrome escatológico su principio; y, obviamente, su fin. Su fin final. Corresponde también a la leyenda (y a su transferencia histórica) el expediente que, en numerosas ocasiones, hace del fin un principio o un comienzo: el instante del fin sería entonces, a la vez, el del inicio: un momento in-augural en una nueva geografía, con una nueva humanidad para una nueva historia. Catástrofe genuina que hace de ese día, de ese momento, de ese punto, instancia simultánea o sucesivamente temida y anhelada. Desde las viejas cosmo(a)gonías, aquellas que vaticinan terremoto, inundación y guerra, hasta las "nuevas" (o, al menos, modernas) sociodiceas que ora temen el rigor de un final técnica e industrialmente motivado, ora llaman, de nuevo y ya de viejo, a ponerse al día (Allons enfants de la Patrie, le jour de gloire est arrivé!...) o convocan a la lucha, a la última, obviamente (Agrupémonos todos en la lucha final...).

Quizá por eso, quizá porque las estructuras narrativas nos cantan y nos cuentan, o quizá porque el tiempo "natural", individual y socialmente comprehendido, que convive sin conflicto y sin servidumbre con el de la mecánica clásica (e incluso con 
el de la mecánica cuántica), es una magnitud susceptible de aceleraciones y ralentizaciones, la auténtica revelación es la revelación del fin(al). Que es, a la vez, revelación del principio. O revelación de la general y total con-figuración del tiempo.

Sin duda, la (im)presión de la forma narrativa, y la impronta que transmite a los hábitos individuales y colectivos, se acentúa cuando la forma es norma, cuando el texto (o los textos) que configuran el síndrome escatológico no sólo tienen estatuto ejemplar, no sólo se veneran como parte de la historia o de la leyenda revestidos con la dignidad de "clásicos", sino que exhiben, pletóricos, capacidad normativa y fuerza de ley. Genuinamente "sagrados", es decir, apartados, segregados y protegidos, esos textos se ubican en una anterioridad o en una exterioridad, en una altura que rechazan parangón: no son textos como los otros, ni siquiera mejores; se sitúan en otro ámbito y/o en otro nivel. Son documentos constituyentes y constitutivos, constitucionales en el sentido más genuino del término. Muchas son las comunidades - políticas, sociales, culturales- que tienen (o han tenido) textos de ese tipo como base de su constitución real (y, en ocasiones, de su constitución formal).

Las culturas cristianas han estado durante siglos (de hecho, desde mucho antes de su inauguración como tales culturas cristianas) sostenidas y animadas por un acervo documental de ese cariz: un conjunto de embajadas, no del todo coincidentes en el contenido y en la forma de sus propuestas, que han articulado el tiempo y el fin; y con ellos la totalidad de la historia subsumida en la leyenda, la totalidad de los miedos, de las esperanzas y de las desesperaciones, de los anhelos.

No solo la tensión escatológica, sino su plasmación en la forma apocalíptica. Es decir, no sólo una interrogación al respecto de los fines, o una especulación (teológica o no) que atañe a los límites del tiempo o que se pregunta por las postrimerías, sino una autorizada y completa revelación del fin, ya pre-visto, ya pre-dicho, e incluso narrado -como eminente e inminente, en todas y cada una de sus etapascon todo lujo de detalles y, en ocasiones, matizado en una imponente y compleja escenografía.

El Apocalipsis (la Revelación) "de Juan", el libro que cierra -que recapitula- las biblias cristianas, el texto que da nombre a un género, nos incumbe especialmente: pero como ápice, cúspide o epítome de una nutrida e impresionante (nunca mejor empleado el adjetivo) biblioteca: tanto anterior como simultánea y posterior ${ }^{1}$. Pues

\footnotetext{
Sobre el Apocalipsis y la apocalíptica la bibliografía es inmensa. Baste una muestra pertinente para los actuales intereses: Elisabeth Schüssler Fiorenza, Apocalipsis. La visión de un mundo justo, Verbo Divino, Estella, 2010; Anathea Portier-Young, Apocalipsis contra imperio. Teologías de resistencia en el judaísmo antiguo, Verbo Divino, Estella, 2016; Adela Yarbro Collins (ed.), Early christian apocalypticism: genre and social settings (Semeia 36), Society of Biblical Literature, 1986; John J. Collins, Apocalypse: the morphology of a genre (Semeia 14), Society of Biblical Literature, 1979; Richard A. Horsley and John S. Hanson, Bandits, prohets and messiahs: popular movements in the time of Jesus, Trinity Press, Harrisburg, 1985; Paul D. Hanson, The down of apocalyptic. The
} 
desde los apocalipsis judíos, alguno de cuyos fragmentos conservados se remontan al siglo III a. de C., hasta los apocalipsis gnósticos, del segundo y tercer siglo de nuestra era, se va conformando una notable colección de revelaciones: notable por sus dimensiones y sobresaliente por su influencia, que no ha cesado a lo largo de dos milenios ${ }^{2}$. Prueba de ello son, no solo los cuantiosos comentarios, las innumerables glosas, sino la masiva presencia de esas revelaciones, notoriamente del ya mencionado Apocalipsis neotestamentario, en la escultura, en la poesía, en la pintura, en la novela, en la arquitectura o en el cine ¿Podría pesarse y medirse, podría cuantificarse de algún modo, el influjo de esos veintidós extraños capítulos? ¿y el influjo de toda esa plural biblioteca del fin(al)?

Afirmar que el Apocalipsis ${ }^{3}$ es el libro más "leído" de cuantos componen la inmensa biblioteca occidental, o que su mensaje ha condicionado la conciencia colectiva a través de generaciones hasta consolidar una imagen del tiempo y de la historia, puede parecer excesivo. Y, sin embargo, quizá se pueda sostener el exceso -aun como tal exceso- con alguna precisión adicional: desde que se escribiera, a finales del siglo primero de la era común, el Apocalipsis ha sido un texto magnético, tan reverenciado como temido, escrutado y debatido en cada uno de sus versículos, en cada una de sus imágenes y de sus extraños símbolos, en cada una de sus enig-

historical and sociological roots of Jewish apocaliptic escatology, Fortress Press, Minneapolis, 1979; Gerhard von Rad, Der Heilige Krieg im alten Israel, Vanderhoeck \& Ruprecht, Göttingen, 1958; Paul D. Hanson, Political engagement as biblical mandate, Cascade Books, Eugene, 2010; Adela Yarbro Collins, The combat myth in the Book of Revelation, Wipf and Stock, Eugene, 1976; Malcom Bull (ed.), Apocalypse theory and the ends of the world, Blackwell, Oxford, 1995; Elaine H. Pagels, Revelations: visions, prophecy and politics in the Book of Revelation, Penguin, Nueva York, 2012; Paul D. Hanson, Old Testament apocaliptic, Abingdon Press, Nashville, 1987; Dale C. Allison, The end of the ages has come. An early interpretation of the passion and resurrection of Jesus, Wipf and Stock, Eugene, 1985; Jhon G. Gager, Kingdom and community. The social world of early christianity, Prentice Hall, New Jersey, 1975; Dale C. Allison, The historical Christ and the theological Jesus, Erdmans, Michigan, 2009; Robert Louis Wilken, The christians as the romans saw them, Yale University Press, New Haven, 1984; John G. Gager, Who made christianity?: the jewish lives of the apostle Paul, Columbia University Press, Nueva York, 2015; Eduardo Arens y Manuel Díaz Mateos, Apocalipsis. La fuerza de la esperanza, CEP, Lima, 2000; David Hellholm (ed.), Apocalypticism in the Mediterranean world and the near est, J.C.B. Mohr (Paul Siebeck), Tübingen, 1983; Richard A. Horsley, Revolt of the Scribes. Resistence and apocalyptic origins, Fortress Press, Minneapolis, 2010; Dale C. Allison, Jesus of Nazareth: millenarian prophet, Fortress Press, Minneapolis, 1998; Richard A. Horsley, Jesus and the spiral of violence. Popular jewish resistence in roman Palestine, Fortress Press, Minneapolis, 1993; Wayne A. Meeks, In search of the early christians. Selected essays, Yale University Press, New Haven, 2002; Wayne A. Meeks, Los primeros cristianos urbanos. El mundo social del apóstol Pablo, Ediciones Sígueme, Salamanca, 2012; John P. Meier, Un judio marginal. Nueva visión del Jesús histórico, Verbo Divino, Estella, 1998 (4 vols.); Emil Schürer, Historia del pueblo judio en tiempos de Jesús, Ediciones Cristiandad, Madrid, 1985 (2 vols.); Philipp Vielhauer, Historia de la literatura cristiana primitiva, Sígueme, Salamanca, 1991.

${ }^{2}$ Que la apocalíptica cristiana está estrechamente relacionada con la precedente y simultánea apocalíptica judía es una evidencia textual. Y que ambas abrevan en una base documental anterior, que en algunos casos es prolijamente re-citada, tampoco admite réplica. El profetismo -daremos alguna indicación al respecto- es un fondo común, ineludible e ineludido.

${ }^{3}$ Siempre que la palabra "apocalipsis" se escriba con mayúscula inicial y en cursiva se refiere al mencionado libro atribuido a (un) Juan. 
máticas o misteriosas cifras (sin embargo y sin duda exactas), un libro que consuma la historia, que se ubica, literalmente, en el extremo, en el confín de lo visible y de lo pensable, un libro que llama a la batalla, a una guerra final; y por ello, un libro que es preciso tratar con cuidado, como materia explosiva: una lectura "precipitada" puede conducir a la herejía, a cualquier suerte o desgracia de fanatismo. Y, a pesar de todo -y no sin opiniones diversas, incluso adversas- es un libro revelado, quizá la "revelación" por antonomasia (como su propio nombre indica), un libro sagrado, tal vez el más sagrado de la sagrada biblioteca (ta biblia).

Desde que se comenzó a difundir su inquieto e inquietante mensaje han pasado siglos. También han pasado siglos, algunos menos, desde que se consolidó como ley, como Palabra de Dios, ob-ligatoria y necesaria para la salvación. La mayor parte de ese tiempo transcurre en un mundo básicamente iletrado, un mundo en el que la socialización de la idea no se produce sólo ni principalmente a través de la lectura, ni siquiera de esa lectura que se practica en la iglesia, en el recinto sagrado ${ }^{4}$. No, la socialización de la idea se produce, de forma masiva, a través de la imagen, de la pintura y de la escultura; también a través del canto, de la música. Se puede comprobar que las escenas rescatadas del Apocalipsis son las más frecuentemente representadas, y en lugar eminente, tras la imagen de la crucifixión de Jesús, el Cristo, tan estrechamente relacionada, por otra parte, con el fin de los tiempos.

Piénsese tan sólo en la imagen del día: en la multiplicada imagen del Pantocrátor $^{5}$ presidiendo el Juicio Final (ese día terrible y, concedamos, fascinante), con su procesión de salvados y condenados convenientemente dispuestos en los flancos correspondientes, esa imagen que saluda (o espanta) en tantos pórticos (llamados "de la Gloria"), en tantos altares, mayores o menores, en tantas capillas: no sólo en la célebre Sixtina. Esa imagen vale como ejemplo y como argumento: pues todo un argumento, el de la Historia Universal y Total (y aun el de la "posthistoria"), es el que resume esa escena forense, miles de veces reproducida; en infinidad de espacios, en infinidad de tiempos. Complétese esa poderosa imagen con las de corderos degollados, combates entre San Miguel (¡Quién como Dios!) y el demonio, jinetes en número de cuatro..., y se tendrá un abultado catálogo de imaginería sagrada, que se prolonga en la profana: bien en la forma de respetuosa continuación, en la de

\footnotetext{
${ }^{4}$ La Iglesia: cada recinto y, sobre todo, la institución en su totalidad (y en su catolicidad: universalidad), se convirtieron en un momento, o en un proceso -lo veremos al concluir-, en el lugar de emplazamiento, desplazamiento y aplazamiento del fin, en instancia de administración de la imagen del día; en una tecno-logía de control del tiempo y del fin a través de la gestión del relato y de sus misterios.

5 Sobra decir, o no, que tanto la imagen del Pantocrátor como la palabra que lo dice, proceden del Apocalipsis. En el Nuevo Testamento la palabra sólo aparece en ese libro (nueve veces) y una vez en la segunda epístola de San Pablo a los Corintios.
} 
reinterpretación, en la de parodia o en la de sacrilegio ¡y cuántas formas y escenas son posibles todavía!

Si durante muchos siglos la imagen sagrada fue el procedimiento predominante de educación, y el procedimiento predominante de extensión, fijación y examen del vínculo social, puede colegirse el efecto de esas imágenes, de su glosa desde los púlpitos, del temor reverencial que habría suscitado su re-citación en el canto, o en la oración. La escenografía, la palabra y la música han funcionado de consuno a lo largo de mucho tiempo para extender una concepción de la historia que -todo lo discutida, alterada, fragmentada o caricaturizada que se quiera- tal vez siga siendo de alguna manera la nuestra. Al menos en el modo de la reliquia, o del residuo, el síndrome escatológico en su versión apocalíptica aún nos sigue (in)formando; o entre-teniendo. Pues si la imagen no ha dejado de re-producirse (y de variarse), hasta Max Beckmann o Anthony Caro ${ }^{6}$ y más allá, más acá, tampoco la melodía ha dejado de sonar, hasta el Quatuor pour la fin du temps de Olivier Messiaen ${ }^{7}$, pieza en la que el Apocalipsis está tensamente actualizado, hasta las innumerables re-visiones en la música popular, o en las bandas sonoras cinematográficas, en las que la articulación de imagen (en movimiento), palabra y música se acerca, cuando logra su mejor registro, al arrogante ideal de la Gesamtkunstwerk.

La multisecular vigencia del discurso apocalíptico en todas sus formas de expresión responde sin duda a la tensión dramática de ese género literario; y a su ambición teórica: nada menos que interpretar el momento presente desde la totalidad de la historia y la totalidad de la historia desde el momento presente. Y el momento presente es el momento de la crisis. Es el momento de la tribulación -e incluso de la Gran Tribulación-, y, por eso mismo, el momento de la decisión: el momento en el que, con la perspectiva del fin, la comunidad se ha de organizar en base a sólidos y genuinos principios. Los textos apocalípticos responden, precisamente, a esa situación de crisis: situación en la que el exilio, la dominación, la explotación..., activan un mecanismo de resistencia, que puede tomar una multiplicidad de formas, incluso (o sobre todo) las formas extremas de interiorización ascética o de exteriorización fanática. De lo que se trata, en cualquier caso, es de una exigencia de justicia que no sólo es ajena sino decididamente hostil a la ley vigente: una ley que es invariablemente sentida e interpretada como tiranía, error, desvío o radical injusticia.

\footnotetext{
${ }_{6}$ Sirviendo, evidentemente, para interpretar otra historia, u otro fragmento de historia, para pre-venir o denunciar otro fin(al). En el (o, más bien, en los) "Apocalipsis" de Max Beckmann, para interpretar el mundo de y desde la Segunda Guerra Mundial; "El Juicio Final”, de Caro: "Era una reflexión sobre la conducta política y social. La historia de Europa está plagada de horrores y mi Juicio Final es una respuesta a las atrocidades de nuestra época”. La explicación, breve y precisa, es del propio escultor.

7 Compuesto, como se sabe, en el campo de concentración de Görlitz, y estrenado allí mismo, en 1941.
} 
De ahí la inquieta e inquietante ambigüedad del modo apocalíptico de resolver la tensión escatológica: no cabe en ese estilo ni pacto ni componenda, no cabe pausado aprendizaje, ni relajada adaptación. Por el contrario, impera la urgencia: ante la inminencia del fin, a la vista del acortamiento del plazo, se impone una decisión radical, absoluta. La verdad de Dios se enfrenta, a muerte, contra la mentira del mundo, o contra el ejército, poderoso, de un agente del mal que ha hecho del mundo injusticia y falsía. No cabe reparación: lo urgente (no sólo lo necesario, u obligatorio), es una radical transformación, una absoluta conversión (metanóia, es el término comúnmente empleado en el Nuevo Testamento); un nuevo hombre para un nuevo mundo en un nuevo tiempo. El resto es destrucción, el resto es muerte. Dado que la justicia y el mundo son incompatibles, ha de imperar la justicia, se ha de aniquilar el mundo. Empadronada en la provincia de lo sagrado, la comunidad apocalíptica es una comunidad de estrés, una comunidad de inquietud. Es una comunidad a-irada, una comunidad de ira. Nada menos que comunidad de la ira de Dios. Pues la ira de Dios o de los dioses, si no se comparte, se padece: con consecuencias letales.

La memoria de esa ira -de la ira de los dioses- llena la literatura. Ira que no suele ser injusta (aunque puede serlo), pero que resulta destructiva, maldita o fatal; y que tiene, sin embargo, diferentes prestaciones ${ }^{8}$.

Destructiva, maldita o fatal puede ser, por ejemplo, la ira de Aquiles, en el mismo comienzo de la Ilíada ${ }^{9}$, si se evalúan sus consecuencias; no es injusta, sino todo lo contrario, si se considera su causa. Escenario forense (y de juicio y juez estamos hablando y hablaremos a continuación con insistencia) en el que la ira y la venganza, estructuralmente implicadas, se erigen en vehículos de derecho (es decir, de poder) y tal vez en esquemas de justicia. Derecho y poder en principio legítimos; justicia que, ciega, no repara (¿tendría que reparar?) en las consecuencias; ya lo sabemos: fiat iustitia et pereat mundus, como se suele decir en otro idioma.

Las consecuencias son, efectivamente, funestas o aciagas ${ }^{10}$, como funesta $o$ aciaga -ouloméne(n) - es la ira. Participio presente emparentado con ollumi, oullomai, que da oulós, oulón, ouló, la palabra puede estar relacionada también con la "totalidad". No es necesario (aquí): baste decir que el elemento peligroso, nefasto o destructivo presente en la ira de Aquiles no caracteriza sólo a la pasión (la ira). Es epíteto de Aquiles mismo; pero también (y por antonomasia) de Ares. Y de Apolo, y

\footnotetext{
${ }^{8}$ Retomamos aquí lo ya tratado en Juan Barja y Patxi Lanceros, Pasos. Los espacios del nómada, Abada editores, Madrid, 2016.

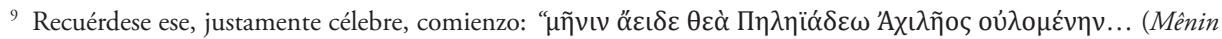
áeide theà Pèlëïádeo Akhilêos ouloménèn...)": "La ira canta, ¡oh diosa!, del pélida Aquiles, funesta...”.

${ }^{10}$ No desde el punto de vista estético: la Ilíada es, precisamente, la consecuencia convertida en canto de la legítima ira de Aquiles. No está mal para empezar (la leyenda): 15.691 versos a-irados, generoso continente de incontables contenidos.
} 
de Afrodita, y de Eros. Funestos o nefastos son (en ciertas circunstancias) los dioses. Destructiva su ira, que es expresión de su poder y arma de su derecho. La cuestión es, sin embargo, o precisamente por ello, de justicia.

La propia palabra latina ira, cuyo origen etimológico es decididamente incierto y ciertamente discutible, puede remitir (o no) a un radical indoeuropeo ${ }^{*} e i(s)$ que sugiere movimiento vertiginoso, acaso brusco (de in-quietud, de infirmitas, se trata, ciertamente); pero también remite a la pasión. Y está presente en la palabra griega ierós (sagrado) ${ }^{11}$.

La ira de Aquiles, sagrada y vertiginosa, es, puede decirse, (in)augural, inicial. Es ese movimiento a-irado de héroe (movimiento que se resuelve en una retirada, en un mutismo hosco y taciturno) el que abre el tiempo de la epopeya. En otros casos, vamos a ellos, la ira es, sobre todo, final: fin de cada biografía y fin de la historia, la ira de Dios es ocasión de un permanente escrutinio; y aguarda el juicio, o la guerra.

Pues el entorno forense y la dimensión agónica de una ira empadronada en el ámbito de lo sagrado no son exclusivas, ni siquiera particularmente características, de las viejas mitologías.

Es claro que los monoteísmos (y quizá ellos sobre todo) tienen su(s) ira $(s)^{12}$. La ira de Alá es casi proverbial. Y puede decirse sin exageración (o con muy poca) que las gentes del judaísmo y de la cristiandad han vivido -y, sobre todo, han muertoacongojadas por la ira de Dios, de esa ira que, precisamente, halla acaso su mejor expresión en el discurso apocalíptico (pero no sólo en él) ${ }^{13}$.

Y no sólo de la ira de Dios entendida de manera difusa, sino de la ira concentrada: las gentes del judaísmo y de la cristiandad han vivido y han muerto pendientes de un día, del día decisivo: el día de la ira, precisamente. Los dioses del Libro, se sabe, comparten rasgos de carácter (tal vez de destino). El registro de sus pasiones (que, sin embargo, pueden inspirar terror) es escaso; su tendencia al pecado...ha-

\footnotetext{
${ }^{11}$ Ha de verse al respecto, siempre sub voce: Pierre Chantraine, Dicctionaire éthymologique de la langue grecque, Klincksieck, París, 1999; Hjialmar Frisk, Griechisches Etymologisches Wörterbuch, Carl Winter Universitäsverlag, Heidelberg, 1970; Alfred Ernout y Antoine Meillet, Dictionnaire etymologique de la langue latine. Histoire des mots, Klincksieck, Paris, 1959; Santiago Segura, Nuevo diccionario etimológico latín-español y de las voces derivadas, Universidad de Deusto, Bilbao, 2013.

12 Eso es lo que, con contundencia, defiende Jan Assmann, Herrschaft und Heil. Politische Theologie in Altägypten, Israel und Europa, Fischer Verlag, Frankfurt 2002 (traducción en Abada editores: Poder y salvación); Das kulturelle Gedächtnis. Schrift, Erinnerung und politische Identität in frühen Hochkulturen, Verlag C. H. Beck, München, 1992; La distinción mosaica. O el precio del monoteísmo, Akal, Madrid, 2006; Religión y memoria cultural. Diez estudios, Lilmod Ediciones, Buenos Aires, 2008; Egipto. Historia de un sentido, Abada, Madrid, 2005; Moisés el egipcio, Oberón, Madrid, 2003; Violencia y monoteísmo, Fragmenta Editorial, Barcelona, 2014; Exodus. Die Revolution der Alten Welt, C. H. Beck Verlag, München, 2015. También Peter Sloterdijk, Gottes Eifer. Vom Kampf der drei Monotheismen, Suhrkamp, Frankfurt, 2007; Im Schatten des Sinai, Suhrkamp, Frankfurt, 2013.

${ }^{13}$ Los testimonios que muestran esa ira en ejercicio son, más que numerosos, innumerables. Y no se concentran tan sólo, aunque es lo que ahora más nos interesa, en el agitado final del Apocalipsis. Ya desde el Génesis, pero sobre todo en y a partir del Éxodo, tienen masiva acogida, que se prolonga a lo largo de los libros históricos y proféticos, por hablar tan sólo de ta biblia (los libros) judíos y cristianos.
} 
bría que decir que nula. No se les conoce propensión a la gula, a la lujuria o a la pereza, tampoco a la avaricia. Habrá quien interprete alguna de sus declaraciones como soberbia(s); habrá quien traduzca su(s) celo(s) como envidia. Pero lo que no se les puede rehusar, sin riesgo de ignorancia o de desacato, es la ira. La ira de Dios es, en cualquiera de las versiones de los tres monoteísmos, una categoría: ineludible. La ira (de Dios) ha sobrecogido durante generaciones; el día de la ira ha sido (tal vez siga siendo, aunque de otro modo) la cita por antonomasia. $Y$ es muy posible, se ha dicho, que incluso nuestra modernidad haya incorporado esa pasión, haya internalizado la estructura forense: al fin y al cabo, en una de sus versiones, la conciencia es tribunal. La geo-grafía y la geo-logía morales de occidente han estado atravesadas, o han sido en buena parte configuradas, por esa ira a la que no se puede llamar, sin cautelas, furia, o cólera; por una ira funesta o terrorífica, sí. Pero por una ira que no es injusta: es, por el contrario, la figura misma de la justicia en ejercicio.

No se va a recorrer aquí ni la larga historia ni la vasta leyenda de esa ira sagrada que concentra toda la revelación en un día. No se va a reparar en cómo esa santa pasión ha configurado la política y el derecho, de cómo ha decidido sobre la moral y sobre la totalidad de la cultura. Interesa, a modo de ejemplo de la pertinaz presencia de la que venimos hablando, una pequeña parte de la de por sí inabarcable versión estética de la ira divina: la que se concentra y estalla en un himno de sobra conocido: el Dies Irae, el Día de la Ira.

Dies ire, dies illa,

Solvet saclum in favilla, Teste David cum Sibylla!

Quantus tremor est futurus, quando iudex est venturus, cuncta stricte discussurus!

$$
\text { [...] }
$$

Iudex ergo cum sedebit, quidquid latet apparebit, nibil inultum remanebit.

Quid sum miser tunc dicturus?

Quem patronum rogaturus,

cum vix iustus sit securus?

Rex tremenda maiestatis, qui salvandos salvas gratis, salva me, fons pietatis... 
Que es, obviamente, día de la ira o día de Dios (o el día de la ira de Dios) -con todos los inquietantes deslizamientos y asociaciones que en la presunta disyuntiva o en la secuencia genitiva se insinúan-, ya que la letra re-cita, entre otros pasajes bíblicos, el impresionante primer capítulo del libro de Sofonías, sobre todo en sus versículos 14-18, el día de Yahvé, precisamente. Así habla el profeta: "Se acerca el gran día de Yahvé, viene presuroso; el estruendo del día de Yahvé es horrible, hasta los fuertes dan gritos amargos. Día de ira es aquel, día de angustia y de congoja, día de ruina y de asolamiento, día de tinieblas y oscuridad, día de sombras y densos nublados, día de trompeta y alarma en las ciudades fuertes y en las altas torres. Aterraré a los hombres, que andarán como ciegos; por haber pecado contra Yahvé su sangre será derramada como se derrama el polvo, y tirados sus cadáveres como el estiércol. Ni su oro ni su plata podrán librarlos en el día de la ira de Yahvé, pues toda la tierra será consumida en el fuego de su furor, pues consumará la ruina, la pérdida repentina de todos los moradores de la tierra" ${ }^{14}$.

Compuesto en el siglo XIII, desde el XIV y al menos hasta la década de los setenta del pasado siglo el Dies Irae forma(ba) parte del Oficio de Difuntos o Misa de Requiem en la liturgia católica. De atribución dudosa (entre los candidatos a la autoría se hallan, junto al probable Tomás de Celano, nada menos que Gregorio Magno, papa, o san Bernardo de Claraval), ese himno, que con toda seguridad ha co-accionado, e intimidado, a generaciones de fieles, está a la base de una prolongada actividad teórica (filosófica, teológica) pero también, es lo que aquí importa, de una larga tradición artística que recorre, sin sorpresa, la historia de la música (con incontables y excelentes versiones: Morales, Victoria, Mozart, Schubert, Liszt, Berlioz, Brahms, Verdi, Mahler, Webber... ${ }^{15}$ ) pero también la de la literatura y la pintura.

Y, como no podía ser menos, el cine ha rendido, en su secular historia, insistentes y memorables visitas a la letra y/o a la música de esa composición ${ }^{16}$ : desde el Faust. Eine deutsche Volkssage de Friedrich Wilhelm Murnau, estrenado en 1926, o la película de Carl Theodor Dreyer (Vredens Dag) conocida, precisamente, como Dies Irae, hasta citas impresionantes (graves algunas, irónicas otras) en Ingmar Bergman (Det sjunde inseglet), Stanley Kubrick (The Shining) o Quentin Tarantino (Kill Bill Vol. 2, Django Unchained) por ejemplo. Incluso en El señor de los anillos (primera y

\footnotetext{
${ }_{14}$ Sin duda, además del profetismo (no sólo Sofonías), también, o sobre todo, está re-citada en el himno la literatura apocalíptica casi al completo, desde Daniel o Henoc hasta el Apocalipsis (de Juan), pasando por los "pequeńos Apocalipsis": Marcos 13, Mateo 24 y Lucas 21, o la apocalíptica paulina, por ejemplo en 1 Tesalonicenses.

15 La lista, como sucederá a continuación cuando se trate de la cinematografía, es incompleta. Es famélica. Completarla sería un trabajo mayúsculo. Y, aquí, innecesario.

${ }^{16}$ El cine, el séptimo arte. Como la séptima trompeta y el séptimo sello, coma la séptima de las lámparas y la séptima de las estrellas, como la séptima de las comunidades y el séptimo de los ángeles: quizá estaba predestinado. O quizá complete y consume una secuencia: justamente apocalíptica.
} 
tercera entregas) de Peter Jackson, en Star Wars o en Mad Max: Fury Road se puede hallar (re)citada la inquieta e inquietante cadencia del Dies Irae. Como se puede colegir a partir de la magra relación, la partitura (y el texto) del himno medieval recorre la historia del cine desde casi sus inicios hasta el estricto presente: ha atravesado todos los posibles escenarios y ha servido para propósitos diversos, pero siempre relacionados con el castigo o el suplicio, con el temor, con el juicio y la sentencia; ya sea en entornos literarios o mitológicos, ya en ambientaciones históricas o alucinatorias, ya con propósito expositivo o crítico. También es cierto que no en todas las películas (citadas o no) tiene el Dies Irae ni el mismo protagonismo ni la misma función, desde luego. Temático, tanto la música como la letra, leída en voz en off en una versión danesa (Vredens Dag som sorten Nat...), en el principio y el final de Vredens Dag: a modo de paréntesis o corchetes que enmarcan la totalidad del relato; crucial en la decisión del destino de Gretchen en Faust; intimidatorio y pronóstico en la sicodélica versión con la que da comienzo El resplandor; tajante en El séptimo sello; índice y factor de una tradición que no cesa en Mad Max: Fury Road, Kill Bill, Star Wars...o abiertamente sardónico: como en la cabalgada del Ku-Klux-Klan en la ya citada Django desencadenado.

Que la crónica de un día - el día de la ira-se prolongue durante tanto tiempo y que se prodigue en los más diversos formatos, que se haya convertido en clave que obstinadamente recorre tanto la historia como la geografía occidental (y, a la postre, mundial) es una cuestión que no carece de relevancia. Tanto la ira de Dios como el día de la ira, ese día -presentido, previsto, predicho y prescrito- que está siempre por venir, son constantes de la historia; $y$ atraviesan tanto la geografía estética como la geografía moral, también la geografía política. Son el compendio de un síndrome escatológico resuelto, desde hace mucho tiempo, en tensión apocalíptica. Pero de un síndrome y de una tensión disciplinados; es decir, institucionalmente contenidos.

"Así, seamos considerados por los hombres como subordinados de(l) Cristo y administradores (domésticos) de los misterios de Dios". Esa es la indicación de San Pablo en la Primera Carta a los Corintios, la misma que se antepone, en griego, como exordio de este ensayo. Y es una indicación altamente eficaz. No sólo o no tanto la que alude a la servidumbre debida al mesías, al ungido -a(l) Cristo-, cuanto la que atañe a la administración doméstica, al carácter de economistas (oíkovó $\mu$ ous) de los misterios de Dios.

La embajada apocalíptica, tanto en el ámbito judío como en el cristiano (allí donde hay una diferencia constatable entre ambos) brota, y se inflama, en ambientes y grupos marginales; no, seguramente, "dejados de la mano de Dios", pero sí con con $(s)$ ciencia de ser olvidados, preteridos o ignorados por otras instancias demasiado humanas. Y, en consecuencia con los modelos, las exaltaciones apocalípticas que en 
la mera historia se han (re)producido, lo han hecho en ambientes de dominación, positivamente sufrida o (inter)subjetivamente sentida.

Excesivamente proclive a la esperanza y por ello proclive a la desesperación, el sujeto apocalíptico vive (y muere) ante la angustia de un fin(al) siempre prometido y siempre postergado; o bajo la presión (altísima presión) de un estrés que, entre certeza e incertidumbre -la certeza del fin, la incertidumbre del día- puede estallar en vehementes procesos auto y heterodestructivos. A la vez que potente dinamizador, el síndrome escatológico en su versión apocalíptica es permanente riesgo de desbordamiento, catarata o alud incontinente e incontenible ${ }^{17}$.

Que los efectos de esa incertidumbre, de esa oscilación, se hallan activos en todo el eón cristiano, es algo que se constata desde los primeros textos: que se mueven entre la seguridad del fin inminente y la angustia por la demora o el retraso.

La institucionalización del relato, su disciplinamiento estructural, consigue -ha conseguido durante siglos- mantener el dinamismo y contener el desbordamiento. Ha conseguido convertir el par certeza-incertidumbre en una eficaz tecno-logía de observación y control. Omnes et singulatim, como decía Foucault, poder pastoral, que se ejerce, por principio y desde el fin(al) sobre todo y sobre todos, o sobre todos y sobre cada uno. Porque todo y todos, insertos en el relato, están, estamos, citados al día y concernidos por el fin.

Que en unos cien años de textos cristianos (en los agitados y fascinantes primeros cien ańos de "cristianografía") se pasara de rezar por el inmediato advenimiento del fin a rezar por su demora (pro mora finis) ${ }^{18}$ es el dato inicial de un proceso que se dilata en el tiempo; que se prolonga en el relato: un tiempo y un relato con fin(al), $y$, por ello, con sentido ${ }^{19}$. Y es la marca inicial de un proceso de administración y control del relato y del día, del tiempo y del fin. "Así, seamos considerados por los hombres como subordinados de(l) Cristo y administradores (domésticos) de los misterios de Dios": economía del misterio, economía del relato y del tiempo, administración tanto de la historia como de la biografía. Porque para todos y cada

\footnotetext{
${ }_{17}$ Véase el estudio clásico de Leon Festinger, Henry W. Riecken y Stanley Schachter, When profecy fails. A social and psychological study of a modern group that predicted the destruction of the world, Harper \& Row, Nueva York, 2009 (original de 1956). Y, sobre todo, el estudio también clásico de Félix Duque, Filosofía para el fin de los tiempos, Akal, Madrid, 2000.

${ }^{18}$ Efectivamente, tanto los evangelios como las cartas de Pablo se escriben desde la certeza del fin inminente; y, progresivamente, desde la certeza de la incertidumbre del día. En Marcos 13, 20 el acortamiento del plazo es don, gracia de Dios: "Y si el Seńor no abreviase aquellos días, no se salvaría nadie, pero en atención a los elegidos que él (mismo) escogió, ha abreviado los días"; Tertuliano, no del todo inmune, sin embargo, a las seducciones del montanismo, ya insta a orar, en su Apologeticum, por los emperadores, por sus servidores, la autoridad, por el bienestar del mundo (de este mundo)... y por el retraso de la final consumación: pro mora finis.

19 Véase, al respecto, el pequeño gran libro de Frank Kermode, El sentido de un final. Estudios sobre la teoría de la ficción, Gedisa, Barcelona, 2000.
} 
uno, para todo, es la cita con el día, el día de la ira, el día de Dios: tan seguro como incierto.

Afirmaba Alcmeón de Crotona (o, al menos, eso dice Aristóteles" ${ }^{20}$ ): "Los hombres mueren porque no son capaces de unir el principio con el fin". La institución y el relato sí son capaces; y quizá por eso no mueren. Quizá por eso se transforman, se prolongan, se prorrogan.

En la determinación del fin (en el doble sentido del genitivo) está la mayor ponencia tanto del relato como de la institución. De ahí la importancia capital de esa administración, de esa economía: de la revelación del fin(al). De la imagen del día.

${ }_{20}$ Problemas, XVII, 3, 916 a. 


\section{Referencias Bibliográficas}

Dale C. Allison, The end of the ages has come. An early interpretation of the passion and resurrection of Jesus, Wipf and Stock, Eugene, 1985.

Dale C. Allison, Jesus of Nazareth: millenarian prophet, Fortress Press, Minneapolis, 1998.

Dale C. Allison, The historical Christ and the theological Jesus, Erdmans, Michigan, 2009.

Jan Assmann, Herrschaft und Heil. Politische Theologie in Altägypten, Israel und Europa, Fischer Verlag, Frankfurt 2002 (traducción en Abada editores: Poder y salvación).

Jan Assmann, Das kulturelle Gedächtnis. Schrift, Erinnerung und politische Identität in frühen Hochkulturen, Verlag C. H. Beck, München, 1992.

Jan Assmann, Moisés el egipcio, Oberón, Madrid, 2003.

Jan Assmann, Egipto. Historia de un sentido, Abada, Madrid, 2005.

Jan Assmann, La distinción mosaica. O el precio del monoteísmo, Akal, Madrid, 2006.

Jan Assmann, Religión y memoria cultural. Diez estudios, Lilmod Ediciones, Buenos Aires, 2008.

Jan Assmann, Violencia y monoteísmo, Fragmenta Editorial, Barcelona, 2014

Jan Assmann, Exodus. Die Revolution der Alten Welt, C. H. Beck Verlag, München, 2015.

Eduardo Arens y Manuel Díaz Mateos, Apocalipsis. La fuerza de la esperanza, CEP, Lima, 2000.

Juan Barja y Patxi Lanceros, Pasos. Los espacios del nómada, Abada editores, Madrid, 2016.

Malcom Bull (ed.), Apocalypse theory and the ends of the world, Blackwell, Oxford, 1995.

Pierre Chantraine, Dicctionaire éthymologique de la langue grecque, Klincksieck, París, 1999.

John J. Collins, Apocalypse: the morphology of a genre (Semeia 14), Society of Biblical Literature, 1979. 
Félix Duque, Filosofía para el fin de los tiempos, Akal, Madrid, 2000.

Alfred Ernout y Antoine Meillet, Dictionnaire etymologique de la langue latine. Histoire des mots, Klincksieck, Paris, 1959.

Leon Festinger, Henry W. Riecken y Stanley Schachter, When profecy fails. A social and psychological study of a modern group that predicted the destruction of the world, Harper \& Row, Nueva York, 2009 (original de 1956).

Hjialmar Frisk, Griechisches Etymologisches Wörterbuch, Carl Winter Universitäsverlag, Heidelberg, 1970.

Jhon G. Gager, Kingdom and community. The social world of early christianity, Prentice Hall, New Jersey, 1975.

John G. Gager, Who made christianity?: the jewish lives of the apostle Paul, Columbia University Press, Nueva York, 2015.

Paul D. Hanson, The down of apocalyptic. The historical and sociological roots of Jewish apocaliptic escatology, Fortress Press, Minneapolis, 1979.

Paul D. Hanson, Old Testament apocaliptic, Abingdon Press, Nashville, 1987.

Paul D. Hanson, Political engagement as biblical mandate, Cascade Books, Eugene, 2010.

David Hellholm (ed.), Apocalypticism in the Mediterranean world and the near est, J.C.B. Mohr (Paul Siebeck), Tübingen, 1983.

Richard A. Horsley and John S. Hanson, Bandits, prohets and messiahs: popular movements in the time of Jesus, Trinity Press, Harrisburg, 1985.

Richard A. Horsley, Jesus and the spiral of violence. Popular jewish resistence in roman Palestine, Fortress Press, Minneapolis, 1993.

Richard A. Horsley, Revolt of the Scribes. Resistence and apocalyptic origins, Fortress Press, Minneapolis, 2010.

Frank Kermode, El sentido de un final. Estudios sobre la teoría de la ficción, Gedisa, Barcelona, 2000.

Wayne A. Meeks, In search of the early christians. Selected essays, Yale University Press, New Haven, 2002.

Wayne A. Meeks, Los primeros cristianos urbanos. El mundo social del apóstol Pablo, Ediciones Sígueme, Salamanca, 2012. 
John P. Meier, Un judio marginal. Nueva visión del Jesús histórico, Verbo Divino, Estella, 1998 (4 vols.).

Elaine H. Pagels, Revelations: visions, prophecy and politics in the Book of Revelation, Penguin, Nueva York, 2012.

Anathea Portier-Young, Apocalipsis contra imperio. Teologias de resistencia en el judaismo antiguo, Verbo Divino, Estella, 2016.

Emil Schürer, Historia del pueblo judio en tiempos de Jesús, Ediciones Cristiandad, Madrid, 1985 (2 vols.).

Elisabeth Schüssler Fiorenza, Apocalipsis. La visión de un mundo justo, Verbo Divino, Estella, 2010.

Santiago Segura, Nuevo diccionario etimológico latín-español y de las voces derivadas, Universidad de Deusto, Bilbao, 2013.

Peter Sloterdijk, Gottes Eifer. Vom Kampf der drei Monotheismen, Suhrkamp, Frankfurt, 2007.

Peter Sloterdijk, Im Schatten des Sinai, Suhrkamp, Frankfurt, 2013.

Philipp Vielhauer, Historia de la literatura cristiana primitiva, Sígueme, Salamanca, 1991.

Gerhard von Rad, Der Heilige Krieg im alten Israel, Vanderhoeck \& Ruprecht, Göttingen, 1958.

Robert Louis Wilken, The christians as the romans saw them, Yale University Press, New Haven, 1984.

Adela Yarbro Collins, The combat myth in the Book of Revelation, Wipf and Stock, Eugene, 1976.

Adela Yarbro Collins (ed.), Early christian apocalypticism: genre and social settings (Semeia 36), Society of Biblical Literature, 1986.

DOI: http://dx.doi.org/10.15366/bp2018.19.002

Bajo Palabra. II Época. No19. Pgs: 49-66 